\title{
Postgraduate Competence and Academic Research Performance: The Mediating Role of Psychological Capital
}

\author{
Jinyuan Guo ${ }^{1}$, Zhixia Chen ${ }^{1, *(1)}$ and Binyao Zheng ${ }^{2}$ \\ 1 College of Public Administration, Huazhong University of Science and Technology, Wuhan 430074, China; \\ gjy2018@hust.edu.cn \\ 2 Department of Education, Kennesaw State University, Kennesaw, GA 30144, USA; bzheng@kennesaw.edu \\ * Correspondence: zhxchen@hust.edu.cn
}

check for updates

Citation: Guo, J.; Chen, Z.; Zheng, B. Postgraduate Competence and

Academic Research Performance: The Mediating Role of Psychological Capital. Sustainability 2021, 13, 6469. https://doi.org/10.3390/su13116469

Academic Editor:

Jesús-Nicasio García-Sánchez

Received: 26 April 2021

Accepted: 28 May 2021

Published: 7 June 2021

Publisher's Note: MDPI stays neutral with regard to jurisdictional claims in published maps and institutional affiliations.

Copyright: (c) 2021 by the authors. Licensee MDPI, Basel, Switzerland. This article is an open access article distributed under the terms and conditions of the Creative Commons Attribution (CC BY) license (https:// creativecommons.org/licenses/by/ $4.0 /)$.

\begin{abstract}
In this study, we developed and validated an instrument for measuring postgraduate competence and examined the relationships between postgraduate competence and academic research performance, along with the mediating role of psychological capital. Based on two independent samples, the results provided robust evidence of postgraduate competence composed of six dimensions. Adopting a two-wave survey at two different time periods, we conducted a questionnaire survey on 364 postgraduates from three top universities in China by random sampling. The results indicated that postgraduate competence was positively associated with academic research performance. Among the competences composed of six dimensions, research ability was the most predictive dimension of academic research performance. Additionally, psychological capital partially mediated the relationship between postgraduate competence and academic research performance. These findings contributed to the ongoing discussion about improving postgraduates' academic research performance under the circumstance of competence-based education.
\end{abstract}

Keywords: postgraduate competence; psychological capital; academic research performance

\section{Introduction}

Education is considered to be a crucial element in the shift towards greater sustainability and a more sustainable world from a very early age [1]. The importance of education, and higher education in particular, for achieving sustainable development is highlighted in the formulation of the sustainable development goals [2]. Indeed, higher education institutions play an essential role in societal transformation toward sustainability through their scientific research and invention [3]. Higher education has produced a large number of scientific and technological talents who engage in scientific research activities, promote the development of science and technology, and provide technical tools for the sustainable development of human activities. Therefore, there is international consensus on the concept that to attain a sustainable world, it is necessary that institutions of higher education encourage their students to acquire the academic research competence needed to be able to enhance technological innovation and advancement [4].

Highly educated personnel play a central role in supporting national sustainable development and ensuring national security in modernization [5-7]. Indeed, studies have found that the academic research of highly educated personnel has a positive effect on promoting sustainable development in the sciences as well as in practice. In light of this, among the most pressing concerns today in the field of higher education research is how to gain greater insight into the phenomenon of postgraduate academic research, of which academic research performance is a fundamental variable [8,9]. Academic research performance suggests the students' academic achievements and related learning outcomes and reflects their learning motivation as well as active engagement in academic research $[10,11]$. There is also evidence suggesting that academic research performance is associated with various sets of technological innovation and sustainable development in society $[12,13]$. The influence of academic research 
performance on a variety of important outcomes has led to a growing interest among researchers in identifying the antecedents of academic research performance. Recently, the topic of postgraduate competence has been attracting increasing amounts of attention in the field of academic research performance. It has become important for universities to help students to enhance the competence required by academic research activities for the promotion of sustainability in social and economic development.

Although there is growing interest in identifying the variables of competence that enhance postgraduate academic research performance, there is also a lack of understanding of the mechanisms involved in it. Firstly, the scales for measuring undergraduates' ability have directly been used to measure postgraduate competence in previous studies [14]. However, these scales are limited because they do not reflect the characteristics of postgraduate academic training that emphasize knowledge innovation and creation within a challenging environment, which differ from those that emphasize the general learning environment for undergraduates [15]. Thus, an appropriate instrument for measuring postgraduate competence needs to be developed to reflect the characteristics of the postgraduate students' learning environments. Secondly, despite there being a small amount of works that confirm the positive relationship between competence and academic performance, it is still unresolved as to which of the more specific aspects of postgraduate competence are linked to academic performance [16]. Several studies have examined competence as a unidimensional construct, making it hard to clearly understand the relationships between different dimensions of competence and academic research performance [16,17]. The roles of the different dimensions of competence in fostering postgraduate students' academic research performance need further investigation. Finally, the mechanism of how postgraduate competence influences academic research performance is still unclear. Psychological capital is defined as a state-like positive psychological construct that is highly involved in task performance and goal achievement [18]. However, few studies have empirically explored whether psychological capital can play a mediating role between postgraduate competence and academic research performance. These unknown factors constitute the objective of this study.

Thus, the current study aimed to extend previous research in the following ways. Firstly, from professional researchers' and postgraduates' perspectives, this work executed a pilot study to develop a reliable and valid measure of postgraduate competence based on postgraduate students' educational background in China. Secondly, the study examined the effect of postgraduate competence, specifically the effects of the different dimensions of postgraduate competence, on their academic research performance. Thirdly, the mediating role of psychological capital on the relationship between postgraduate competence and academic research performance was explored. The study provides a more accurate and suitable measuring instrument for postgraduate competence. Moreover, it helps to further our understanding of the role of postgraduate competence and psychological capital in the formation of academic research performance.

The rest of this article is organized as follows. The second part briefly reviews the relevant literature and several corresponding hypotheses drawn from previous research. The third part discusses a pilot study executed to develop and validate the measure of postgraduate competence. The fourth section introduces the methods of the main study, which includes information about participants and procedures, and the instruments used in this study. The next section presents the data analyses and empirical results based on the path analysis and a set of regression analyses. Finally, we show the related discussion and conclusions emerging from this study, and discuss possible implications, limitations, as well as future research directions. 


\section{Literature Review and Hypothesis Development}

\subsection{Postgraduate Competence}

Competence has been defined by numerous researchers in the existing literature. Generally, competence is considered a composite of the knowledge, skills, motivations, and attitudes required to adequately undertake a task or intellectual process that is appropriate for professional performance in a defined context $[19,20]$. It refers to the underlying characteristics of individuals that distinguish those who have outstanding achievements in a certain job from those who perform poorly [21]. The theoretical approach with the concept of competence and its practical applicability have been employed in the field of education [22], thus forming competence-based education. The competence-based education models emphasize competence development, and development means improving knowledge, skills, and attitudes, which is different from the traditional university teaching model based on knowledge transmission [23]. In this context, several authors have proposed models to evaluate competences in higher education, including dimensions for measuring competences.

The components of students' competence have been explored by researchers in various ways. Asif et al. [24] proposed a model for total quality management in higher education that includes different critical success factors. Durette et al. [8] established a reference framework through a survey of $2794 \mathrm{PhDs}$, including 111 competences. Gómez et al. [22] used a sample of 351 student reports provided by professionals to conduct a two-year follow-up of social science students. Van Loo and Semeijn [25] considered that competence can be measured by using self-reports or through expert ratings provided by key informants or observers. For these research works, the main variables that comprise competence are the following: communication, leadership, accuracy, autonomy, planning and organization, information technology, reflective capacity, teamwork and capacity to address changes, professional knowledge, creativity, and initiative [22,26].

In the process of assessing competence, these analyses have focused primarily on student perceptions. Nevertheless, some authors suggest that competences can be measured using the opinions of professional experts [22,27]. Additionally, most of the existing competence scales are developed for undergraduate students and a few for postgraduate students. The characteristics of the learning environment and training objectives of the two are very different. It may lead to the deviation and inaccuracy of the results if the scale of an undergraduate's competence is directly measured against the postgraduate's competence. Furthermore, although some researchers have analyzed and emphasized the importance of psychological quality in postgraduate training, psychological quality has not been taken into account in most of the research conducted on competence $[28,29]$. The Chinese context presents certain particularities because with the pressure from study, economy, employment, marriage, and other aspects, the psychological pressure experienced by postgraduate students is increasing day by day. It is necessary for postgraduate students to have good psychological quality. Therefore, one objective of this study is to develop a scale of postgraduate competences based on the perspectives of both professionals and students.

\subsection{Academic Research Performance}

Academic research performance is one of the most relevant outcomes in the university setting [18]. It refers to the behaviors and achievements that students have acquired in a university program. Excellence in academic research performance refers to a high level of theoretical, practical, and technical knowledge, active learning behaviors, and the capacity to achieve academic goals [30]. Academic research performance has been conceptualized as encompassing three aspects: academic research attitude performance, academic research behavior performance, and academic research output performance [31,32]. Academic research attitude performance focuses on students' learning motivation as well as positive attitudes. Students' academic research attitude has consistently been found to be related to a wide range of important qualities, such as high persistence, increased effort, and challenge seeking. Academic research behavior performance focuses on students engaging in a task 
with the purpose of learning, understanding, and improving their skills, and attributing their success to efforts [33]. Students with a high level of academic research behavior strive to participate in various academic activities and make use of effective learning strategies to enhance their abilities. Academic research output performance focuses on students academic achievements and productivities. Students who pursue academic research goals strive to avoid doing worse than others or appear incompetent relative to others. They use self-reference standards to evaluate their learning outcomes and attribute their success to their efforts [34].

\subsection{Postgraduate Competence and Academic Research Performance}

Competence theory emphasizes that individuals with a deep set of characteristics such as motivation, traits, attitudes, or values can perform better at work because they can apply competences to different problems and tasks when exposed to challenging situations [35]. Competence, which is made up of various core parts or elements, has the structural elements of performance requirements, and it can be observed and adjusted to obtain high performance [36]. Postgraduate competence represents the positive ability and resources that individuals possess, which enable them to work through challenging assignments and move towards flourishing and success [37]. Postgraduate students with high competence can better cope with the various kinds of demands they face in academic research and are more willing to spend additional energy and effort on completing academic tasks, and hence be more involved when performing research with a high level of absorption. In addition, postgraduate competence including the professional knowledge and research abilities that can be used successfully in different professional situations help postgraduate students to meet the demands of their academic research output and result in positive personal outcomes such as academic performance.

Previous researchers have confirmed the association between competence and performance under educational circumstances, showing that students with competences achieve better academic performance. Ferla et al. [38] demonstrated that students' selfperceived academic competence influences student learning and academic performance. Ren et al. [39] confirmed that students' critical thinking of academic ability had a significant impact on academic performance. Hu et al. [40] developed an innovative culinary competence curriculum model, which was effective for improving students' grades and innovative performance. Nwosu et al. [17] proved that information literacy skills or competences, which were determinants of academic achievement, significantly improved students' academic performance. With the existence of substantial evidence as described by the literature, we expect that postgraduate competence is positively associated with academic research performance.

\subsection{The Mediating Role of Psychological Capital}

Within contemporary writings on psychological capital, this concept has received considerable attention as an important element of an individual's positive psychological resources. Psychological capital is an intrinsic and stable psychological trait exhibited during individuals' growth and development [41]. It is considered to be a state-like positive psychological construct that is highly involved in task performance and reaching goals [18]. As a collection of core qualities and capabilities, the competence has an effect on psychological capital. The shaping of postgraduate competence stimulates positive emotions and passion that help postgraduate students to gain the psychological resources and motivation needed to achieve goals $[42,43]$. To improve students' psychological capital and achieve the purpose of attracting students to earnestly study, Liao and Liu [44] adopted a psychological intervention model for building the competence of students. Bouzari and Karatepe [45] pointed out that salespeople were high on psychological capital when they had the ability to influence the work environment and had freedom to state their opinions and make decisions about the job. 
Psychological capital is a set of positive psychological resources that contains lowerorder variables such as self-efficacy, optimism, hope, and resilience [46]. Under numerous challenging academic situations, postgraduate students may need a high level of selfefficacy to exert the necessary energy and effort to complete tasks or assignments. Likewise, optimistic individuals consider their own stabilizing factors as the cause of success, while external temporary factors explain failure. Academic research requires continuous investment of time and effort, and its outcomes require longer periods of time. If the ideal output is not obtained in the short term, they tend to attribute the cause to external temporary factors rather than sulk in self-blame for incompetence and will spend more time and effort in order to achieve goals. If the students achieve staged results, they will expect higher performance, generate positive self-fulfillment prophecies, and subsequently work hard to improve academic research performance. Finally, hope and resilience become important psychological resources when persevering towards the achievement of academic goals when problems and adversity appear. Ortega-Maldonado and Salanova [18] found that college students' psychological capital is directly related to learning performance, highlighting the importance of psychological capital in academic settings. Luthans et al. [47] found a predictive relationship between psychological capital and performance among business students. Ouweneel, Le Blanc, and Schaufeli [48] found that students' self-efficacy, hope, and optimism predicted future academic engagement. This reasoning led us to propose that psychological capital mediates the positive relationship between postgraduate competence and academic research performance.

The hypothesized model to be tested in this study is provided in Figure 1.

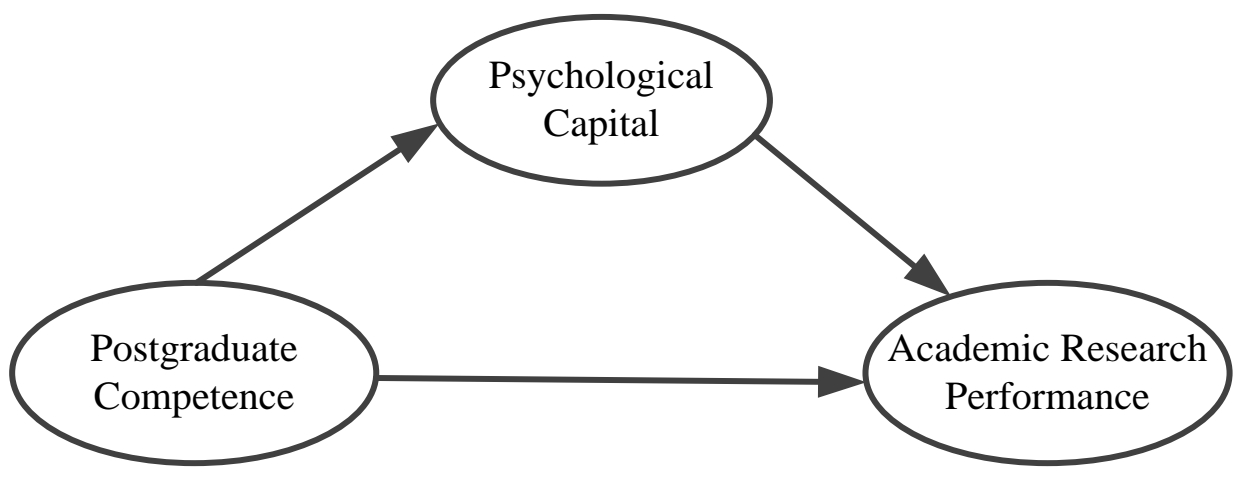

Figure 1. Hypothesized model.

\section{Pilot Study}

The existing scales for measuring postgraduate competence are lacking in evidence of validity [20]. Additionally, the Chinese context presents certain particularities since the plan for world-class universities and first-class disciplines is relatively recent in China, and pays special attention to students' competences. Following Gómez et al. [22], we developed a reliable and valid measure of postgraduate competence based on the Chinese educational context and the actual performance of Chinese postgraduate students. The process involved two steps. In step 1, we generated items for the six dimensions of the postgraduate competence scales. In step 2, we refined the new scale and evaluated the reliability and validity of all scales through exploratory and confirmatory factor analysis. 


\subsection{Step 1: Item Generation}

We developed new items using deductive and inductive approaches [49]. We began with a deductive approach as the relevant literature concerning various competences provides sufficient theoretical grounding for item generation. This approach generated nineteen items for postgraduate competence. We then invited 13 experts (five professors, eight student counselors) to participate in an inductive item-generation exercise to ensure the adequacy of the content of postgraduate competence. The five professors were professional researchers on educational management. The eight student counselors had substantial consulting experience with students. We provided the participants with explanations of postgraduate competence and asked them to recall examples of students who matched these explanations. After proposing items based on their experience, they reviewed the eighteen items that we derived from the deductive process. A total of 37 items were obtained in this process. All items were written in Chinese.

We invited 12 doctoral students, trained in psychometrics and education research, to sort these items on the basis of the contents. Among the 37 items, 10 items pertained to self-management (SM); 10 items pertained to research abilities (RB); 6 items pertained to attitude qualities (AQ); 4 items pertained to psychological qualities (PQ); 4 items pertained to research methods (RM); 3 items pertained to professional knowledge (PK).

\subsection{Step 2: Construct Validation}

To ascertain the components of postgraduate competence, we conducted a survey in which respondents were master and doctoral students majoring in management, economics, and education at five universities in Wuhan. A letter of introduction attached to the questionnaire explained the objective of the survey as an investigation into their perceptions of postgraduate competence and assured them that it was voluntary and confidential. Questionnaires were distributed to 232 students, randomly selected by their professors. Response options ranged from $1=$ "strongly disagree" to $5=$ "strongly agree". Of the 232 students, 202 returned usable questionnaires, at a response rate of $87.1 \%$. On average, students were 22.7 years old (S.D. $=1.03$ ), and 58.9 percent were females. We conducted an exploratory factor analysis (EFA) to uncover the underlying factor structure of postgraduate competence, as assessed in step 1 . As shown in Table 1, the rotated factor matrix produced six suitable factors: (1) SM, 5 items; (2) RB, 8 items; (3) AQ, 6 items; (4) PQ, 3 items; (5) RM, 4 items; and (6) PK, 3 items. Eight items were eliminated because of low factor loadings or high cross-factor loadings. Eigenvalues of the six factors ranged from 1.528 to 6.741 , with $66.05 \%$ of total variance explained. Reliabilities for each dimension were above 0.8 .

We also performed a confirmatory factor analysis (CFA) to test the factor structure of the 29 postgraduate competences represented by our items. We collected valid data from 271 full-time undergraduate students in Wuhan. Professors invited students to voluntarily participate in a survey administered after class. On average, the students were 23.8 years old (S.D. $=0.50$ ) and $56.8 \%$ were females. The survey was presented in Chinese and used the same 5-point scale. RMSEA, TLI, and CFI are normally chosen as indices to evaluate the models' goodness of fit for contrasting models. As for the RMSEA, a value less than 0.08 is interpreted as good fit. TLI and CFI values greater than or equal to 0.90 indicate adequate fit [50]. We examined whether each item significantly loaded on its a-priori factor and deleted items with modification indices higher than 10 [51]. 
Table 1. Factor analysis results of the postgraduate competence scale.

\begin{tabular}{|c|c|c|c|c|c|c|c|c|}
\hline Dimensions & Factors and Items & EFA Loadings ${ }^{a}$ & $\begin{array}{l}\text { \%Variance } \\
\text { Explained }\end{array}$ & Cronbach's $\alpha$ & CFA Loadings $b$ & Cronbach's $\alpha$ & CR & AVE \\
\hline \multirow{4}{*}{$\begin{array}{l}\text { Self-management } \\
\qquad(\mathrm{SM})\end{array}$} & I have good skills of time management. & 0.745 & \multirow{4}{*}{32.830} & \multirow{4}{*}{0.907} & 0.664 & \multirow{4}{*}{0.918} & \multirow{4}{*}{0.913} & \multirow{4}{*}{0.680} \\
\hline & I am a person with strong self-management ability. & 0.723 & & & 0.842 & & & \\
\hline & I can make plan and be self-organized. & 0.579 & & & 0.883 & & & \\
\hline & I keep strong initiative during my graduate studies. & 0.433 & & & 0.798 & & & \\
\hline \multirow{5}{*}{$\begin{array}{l}\text { Research abilities } \\
\text { (RA) }\end{array}$} & I am able to propose valuable academic questions. & 0.762 & \multirow{5}{*}{3.807} & \multirow{5}{*}{0.918} & 0.753 & \multirow{5}{*}{0.922} & \multirow{5}{*}{0.910} & \multirow{5}{*}{0.669} \\
\hline & I can think with critically. & 0.707 & & & 0.871 & & & \\
\hline & I have a strong ability of abstract thinking. & 0.679 & & & 0.805 & & & \\
\hline & I can properly design the research process. & 0.672 & & & 0.828 & & & \\
\hline & I can do the scientific research on my own. & 0.594 & & & 0.827 & & & \\
\hline \multirow{6}{*}{$\begin{array}{l}\text { Attitude qualities } \\
\text { (AQ) }\end{array}$} & I am a person of integrity. & 0.799 & \multirow{6}{*}{2.392} & \multirow{6}{*}{0.922} & 0.805 & \multirow{6}{*}{0.923} & \multirow{6}{*}{0.918} & \multirow{6}{*}{0.650} \\
\hline & I abide by the law. & 0.771 & & & 0.803 & & & \\
\hline & I have right values. & 0.751 & & & 0.810 & & & \\
\hline & I'm a practical person pursuing the reality. & 0.710 & & & 0.804 & & & \\
\hline & I act under the regulations. & 0.697 & & & 0.804 & & & \\
\hline & I, myself, a gratitude person. & 0.690 & & & 0.811 & & & \\
\hline \multirow{2}{*}{$\begin{array}{l}\text { Psychological } \\
\text { qualities (PQ) }\end{array}$} & I have a strong capacity of mental adjustment. & 0.717 & \multirow[t]{2}{*}{2.052} & \multirow[t]{2}{*}{0.880} & 0.909 & \multirow[t]{2}{*}{0.915} & \multirow[t]{2}{*}{0.912} & \multirow[t]{2}{*}{0.776} \\
\hline & I'm in good condition. & 0.685 & & & 0.814 & & & \\
\hline \multirow{4}{*}{$\begin{array}{l}\text { Research methods } \\
\text { (RM) }\end{array}$} & I do computer-operation and application well. & 0.814 & \multirow{4}{*}{1.647} & \multirow{4}{*}{0.807} & 0.547 & \multirow{4}{*}{0.832} & \multirow{4}{*}{0.833} & \multirow{4}{*}{0.568} \\
\hline & $\begin{array}{c}\text { I do well in mathematical modeling and } \\
\text { quantitative analysis. }\end{array}$ & 0.788 & & & 0.796 & & & \\
\hline & I am adept at data-analysis. & 0.679 & & & 0.981 & & & \\
\hline & I have acquired interdisciplinary knowledge. & 0.496 & & & 0.612 & & & \\
\hline \multirow{4}{*}{$\begin{array}{c}\text { Professional } \\
\text { knowledge (PK) }\end{array}$} & I have a solid foundation of professional & 0.740 & & & 0.868 & & & \\
\hline & $\begin{array}{l}\text { knowledge. } \\
\text { I am familiar with the cutting-edge/frontier }\end{array}$ & & 1.528 & 0.805 & & 0.910 & 0.911 & 0.773 \\
\hline & $\begin{array}{l}\text { I am familiar with the cutting-edge/trontier } \\
\text { knowledge of my major. }\end{array}$ & 0.707 & & & 0.878 & & & \\
\hline & My knowledge structure is sound and reasonable. & 0.654 & & & 0.891 & & & \\
\hline
\end{tabular}

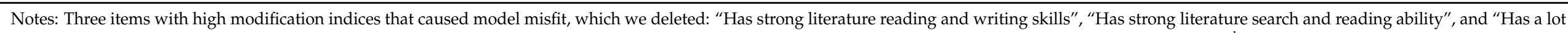
of academic research experience". ${ }^{a} N=202$. The extraction method for EFA is principal axis analysis. The rotation method is varimax, with Kaiser normalization. ${ }^{b} N=271$. 
Results showed three items with high modification indices that caused model misfit, which we deleted. The remaining 26 items demonstrated satisfactory goodness-of-fit indices $(\chi 2 / d f=2.264, p<0.05 ; \mathrm{CFI}=0.965$, TLI $=0.959$, and RMSEA $=0.068)$. The factor loadings of the postgraduate competence model are presented in the right column of Table 1. All items significantly loaded on their intended factors, and the standardized loadings ranged from 0.547 to 0.916 . The composite reliability of the dimensions ranged from 0.833 to 0.918 . Cronbach's alphas for each dimension were above 0.805 . Correlation coefficients among six dimensions were from 0.362 to 0.701 (correlations and reliabilities of postgraduate competence dimensions are available on request). Average variances extracted (AVE) reached the criterion of 0.500 , suggesting that variances captured by the construct are larger than variances resulting from measurement error [52]. The square roots of AVE (from 0.752 to 0.871 ) were larger than the correlation coefficients among the six factors (maximum value was 0.701), demonstrating the discriminant validity of the six-factor structure [52]. We also ran a second-order CFA to test whether the six dimensions were best represented by a higher-order superordinate construct or the theorized multidimensional construct [53]. Results revealed that a second-order factor produced a slightly poorer overall fit $(\chi 2 / d f=2.570, p<0.05 ; \mathrm{CFI}=0.955, \mathrm{TLI}=0.949$, and $\mathrm{RMSEA}=0.076)$ than the six-factor model, suggesting that postgraduate competence is a multidimensional construct composed of six dimensions. From these results, we concluded that the items were reasonable measures of the postgraduate competence dimensions.

\section{Methods of Main Study}

\subsection{Participants}

The sample comprised 364 postgraduate students from three top universities in China by random sampling. The sample features are as follows: 167 males (45.9\%) and 197 females $(54.1 \%) ; 83(22.8 \%)$ in the first year of academic master degree, 86 (23.63\%) in the second year of academic master degree, $61(16.76 \%)$ in the third year of academic master degree, $55(15.11 \%)$ the first year of doctoral study, $47(12.91 \%)$ in the second year of doctoral study, $32(8.79 \%)$ in the third year of doctoral study; 6 (1.6\%) were 20 years old, $277(76.1 \%)$ were in the age range of $21-25$ years old, $77(21.2 \%)$ in the age range of $26-30$ years old, $4(1.1 \%)$ in the age range of 31-35 years old; 187 (51.4\%) were students in science and engineering, and $177(48.6 \%)$ in humanities and social sciences.

\subsection{Instruments}

Postgraduate competence. The scale developed in the pilot study was used to assess postgraduate competence. It included 26 items with 6 subscales: self-management (5 items, sample item: "I have good time management skills."), research abilities (5 items, sample item: "I design the research process properly."), attitude qualities (6 items, sample item: "I follow the rules."), psychological qualities (3 items, sample item: "I have a strong psychological adjustment ability."), research methods (4 items, sample item: "I have strong mathematical modeling and measurement analysis skills.") and professional knowledge (3 items, sample item: "I am familiar with the frontier knowledge of this major."). All items were assessed on a five-point Likert scale ranging from 1 (not at all like me) to 5 (very much like me). The Cronbach alpha coefficient of the postgraduate competence scale was 0.876 , and those of the six sub-scales ranged from 0.826 to 0.848 .

Psychological capital. This was assessed through the Psychological Capital Questionnaire developed by Luthans and Youssef [46]. It included 24 items with 4 subscales: self-efficacy (6 items, sample item: "I believe I can analyze challenging problems and find solutions."), hope (6 items, sample item: "Currently, I am achieving the research goals I set for myself."), resilience (6 items, sample item: "I can usually make strides in pressure.") and optimism (6 items, sample item: "When encountering uncertain things in academic research, I usually look forward to the best results."). Students responded to all items on a Likert scale ranging from 1 (never) to 5 (always). The Cronbach alpha coefficient of the 
psychological capital scale was 0.872 , and those of the four sub-scales ranged from 0.762 to 0.887 .

Academic research performance. This was measured using a 10-item scale adapted from Fromuth et al. [33]. It included 3 subscales: academic research attitude performance (4 items, sample item: "I love my major and am willing to work hard in research."), academic research behavior performance ( 3 items, sample item: "I volunteered for challenging tasks in scientific research."), and academic research achievements performance (3 items, sample item: "I have invested a lot of energy in academic research, and I have some academic research outputs, papers, or monographs."). All items were assessed on a five-point Likert scale ranging from 1 (not at all like me) to 5 (very much like me). The Cronbach alpha coefficient of the academic research performance scale was 0.853 , and those of the three sub-scales were $0.823,0.862$, and 0.847 .

Control Variables. Based on the previous study [54,55], some demographic information and other relevant factors (gender, age, major, and grade) could affect the dependent variables. Therefore, these factors were considered as control variables in the analysis.

\subsection{Procedures}

The participants in this study were postgraduate students studying different majors from three top universities in China. Data were collected in two stages in order to reduce the likelihood of common method variance in self-reported survey data, and each stage was one month apart. Postgraduate competence, psychological capital, and control variables were investigated for the first phase in May 2020. Of the 500 respondents who were asked to participate, 423 returned the survey ( $84.6 \%$ response rate). After an interval of one month, the second survey was distributed to 423 postgraduate students who responded to the first survey in June 2020. The academic research performance was measured in the second phase. Of the 423 participants who completed the first survey, 384 returned the second questionnaire (90.7\% response rate). Nine cases were excluded because of incomplete responses, yielding a total of 375 useful responses. After matching the two questionnaires, 364 valid questionnaires were finally obtained, with a total effective recovery rate of $72.8 \%$.

\subsection{Data Analyses}

The data were organized, analyzed, and treated statistically through two statistical programs in this study. The SPSS v.23 was used for the prior data analyses, as well as for the descriptive and correlational analyses; the AMOS v.23 was used in the prior analyses to assess common method variance and to estimate the proposed structural equation models. More specifically, confirmatory factor analysis, path analysis, and a set of regression analyses were conducted.

\section{Results}

\subsection{Common Method Variance Test}

This study used self-report questionnaires and might have common method variance (CMV). A non-measurable potential method of factor was used to test the existence of common method biases. The common method bias of latent variables is included in the structural equation model [56]. All the items of other measurement constructs were loaded on the common method deviation factor. The comparison included the homology bias factor and the fitness of the model without the condition to test the common deviation effect. After controlling the homologous bias factor, the model CFI, TLI, RMSEA, and other fitting indexes all changed below 0.02 and the change was not significant. Therefore, common method bias was not a concern in the present study.

\subsection{Descriptive and Correlation Statistics}

The means, standard deviations, and correlations among the study variables are presented in Table 2. All the correlations among variables were significant at a level of 0.01 . 
Table 2. Means, standard deviations, and correlation.

\begin{tabular}{cccccccc}
\hline Variables & $\mathbf{1}$ & $\mathbf{2}$ & $\mathbf{3}$ & $\mathbf{4}$ & $\mathbf{5}$ & $\mathbf{6}$ \\
\hline 1. Gender & - & & & & & \\
2. Age & $-0.337^{* *}$ & - & & & & \\
3. Grade & $-0.192^{*}$ & $0.407^{* *}$ & - & & & \\
4. Major & $-0.257^{* *}$ & 0.008 & 0.088 & - & & \\
5. Postgraduate & 0.095 & -0.033 & -0.006 & -0.105 & - & - & \\
$\quad$ competence & 0.049 & 0.014 & -0.072 & -0.030 & $0.745^{* *}$ & & \\
6. Psychological capital & 0.188 & -0.104 & -0.104 & -0.134 & $0.476^{* *}$ & $0.471^{* *}$ & \\
7. Academic research & 1.540 & 2.220 & 1.990 & 4.040 & 3.437 & 3.271 & 3.341 \\
performance & 0.499 & 0.488 & 1.201 & 3.215 & 0.958 & 0.856 & 0.916 \\
Mean & SD & &
\end{tabular}

Notes: $N=364$. Means are based on average factor scores. ${ }^{*} p \leq 0.05 ;{ }^{* *} p \leq 0.01$.

Prior to testing the hypotheses, confirmatory factor analysis (CFA) was conducted using AMOS v.23 to examine the validity of the four main variables used in the study (postgraduate competence, psychological capital, and academic research performance). As the results in Table 3 indicate, the hypothesized three-factor model fitted the collected data well $(\chi 2=156.752, d f=99, \chi 2 / d f=1.583, \mathrm{CFI}=0.980, \mathrm{NFI}=0.947, \mathrm{RMSEA}=0.059)$. Compared to the three-factor model, other models exhibited significantly poorer fits.

Table 3. Results of confirmatory factor analysis.

\begin{tabular}{ccccccc}
\hline Models & $\chi^{2}$ & $d f$ & $\chi^{2 / d f}$ & CFI & NFI & RMSEA \\
\hline Three-factor model: POC; PC; ARP & 156.752 & 99 & 1.583 & 0.980 & 0.947 & 0.059 \\
Two-factor model: POC + PC; ARP & 299.419 & 101 & 2.965 & 0.930 & 0.899 & 0.107 \\
Two-factor model: POC; PC + ARP & 450.971 & 102 & 4.421 & 0.877 & 0.849 & 0.142 \\
One-factor model: POC + PC + ARP & 731.840 & 106 & 6.904 & 0.780 & 0.754 & 0.186 \\
\hline
\end{tabular}

Notes: $\mathrm{POC}=$ postgraduate competence $\mathrm{PC}=$ psychological capital. $\mathrm{ARP}=$ academic research performance + combined into one factor.

\subsection{Different Dimensions of Postgraduate Competence on Academic Research Performance}

In order to examine the relationship between postgraduate competence and academic research performance, a path analysis was conducted by using the AMOS v.23 program. The results of the modified structural equation model produced the following fit indices: $\chi^{2} / d f=1.769, \mathrm{GFI}=0.948, \mathrm{AGFI}=0.901, \mathrm{NFI}=0.960, \mathrm{RFI}=0.932, \mathrm{IFI}=0.982, \mathrm{TLI}=0.969$, $\mathrm{CFI}=0.982$, RMSEA $=0.072$. The result in Figure 2 shows that postgraduate competence positively predicted academic research performance $(\beta=0.63, p<0.001)$.

In order to examine the effects of six dimensions of postgraduate competence on academic research performance, a set of regression analyses were conducted using SPSS v.23. The results of the hierarchical regression analysis are presented in Table 4 . For the academic research attitude performance, research abilities $(\beta=0.447, p<0.001)$, attitude qualities $(\beta=0.112, p<0.01)$, research methods $(\beta=0.143, p<0.01)$, and professional knowledge $(\beta=0.222, p<0.001)$ were positive predictors. These variables explained $63 \%$ of variance in academic research attitude. For the academic research behavior performance, research abilities $(\beta=0.432, p<0.001)$, psychological qualities $(\beta=0.104, p<0.05)$, and professional knowledge $(\beta=0.208, p<0.001)$ were significantly positive, which explained $60.2 \%$ of variance in academic research behavior. For the academic research achievements performance, research abilities $(\beta=0.549, p<0.001)$, attitude qualities $(\beta=0.102, p<0.001)$, and professional knowledge $(\beta=0.162, p<0.05)$ were positive predictors. These variables explained $24.8 \%$ of variance in academic research achievements. 


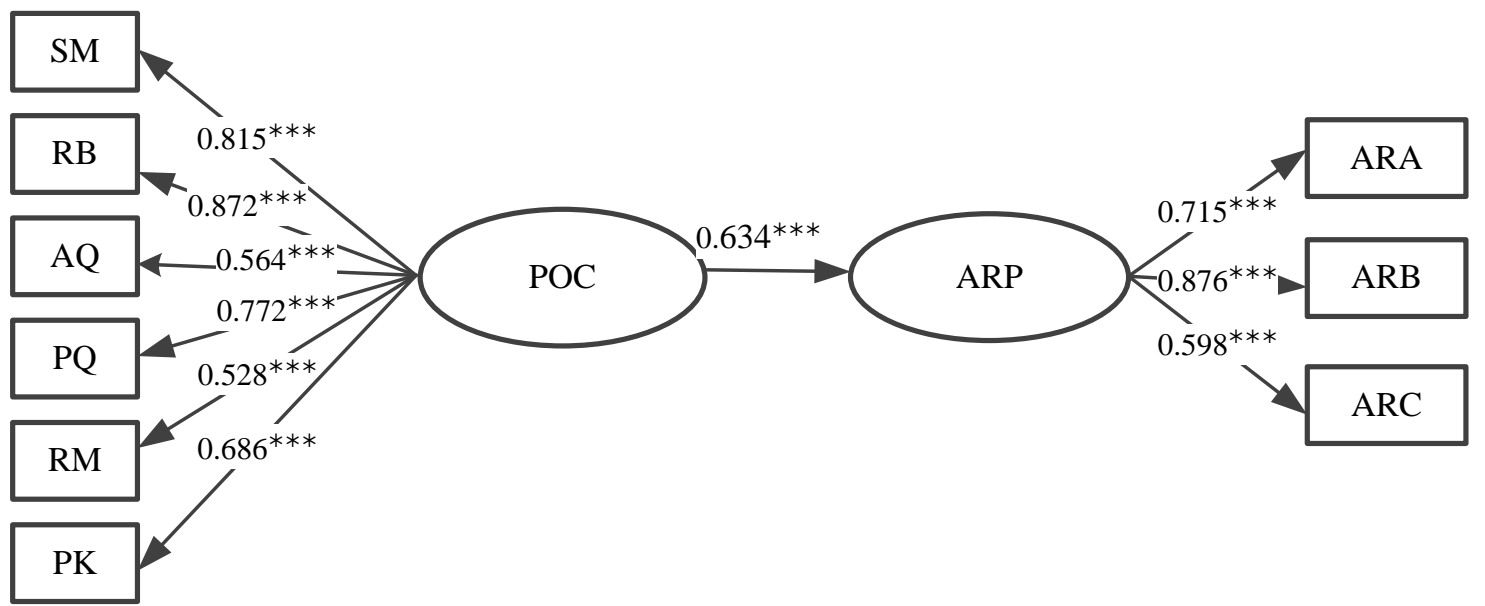

Figure 2. Predictive test of postgraduate competence on academic research performance. Notes: SM = self-management; $\mathrm{RB}=$ research abilities; $\mathrm{AQ}=$ attitude qualities; $\mathrm{PQ}=$ psychological qualities; $\mathrm{RM}=$ research methods; $\mathrm{PK}=$ professional knowledge; $\mathrm{POC}=$ postgraduate competence; $\mathrm{ARP}=$ academic research performance; ARA = academic research attitude; $\mathrm{ARB}=$ academic research behavior; $\mathrm{ARC}=$ academic research achievements. ${ }^{* * *} p \leq 0.001$.

Table 4. Results of six dimensions of postgraduate competence on academic research performance.

\begin{tabular}{cccc}
\hline \multirow{2}{*}{ Variables } & Academic Research Attitude & Academic Research Behavior & $\begin{array}{c}\text { Academic Research } \\
\text { Achievements }\end{array}$ \\
\cline { 2 - 3 } & $\boldsymbol{\beta}$ & $\boldsymbol{\beta}$ & $\boldsymbol{\beta}$ \\
\hline Gender & 0.018 & 0.005 & 0.032 \\
Age & -0.014 & -0.020 .071 \\
Grade & -0.049 & -0.082 & -0.001 \\
Major & 0.028 & 0.053 & -0.049 \\
Self-management & $0.067^{* * *}$ & 0.114 & $0.072^{* *}$ \\
Research abilities & $0.447^{* *}$ & $0.432^{* * *}$ & $0.549^{* * *}$ \\
Attitude qualities & $0.112^{* *}$ & -0.032 & $0.102^{* * *}$ \\
Psychological qualities & $0.090^{* *}$ & $0.104^{*}$ & -0.595 \\
Research methods & $0.143^{* * *}$ & -0.010 & 0.180 \\
Professional knowledge & $0.222^{* * *}$ & $0.208^{* * *}$ & $0.162^{*}$ \\
$\mathrm{R}^{2}$ & $0.644^{* * *}$ & $0.616^{* * *}$ & $0.276^{* * *}$ \\
$\Delta \mathrm{R}^{2}$ & $0.630^{* * *}$ & $0.602^{* * *}$ & $0.248^{* * *}$ \\
\hline
\end{tabular}

Notes: ${ }^{*} p \leq 0.05 ;{ }^{* *} p \leq 0.01 ; * * * \leq 0.001$.

\subsection{Mediating Effect of Psychological Capital}

To probe the mediating role of psychological capital, we followed the approach suggested by Hayes [57]. The SPSS macro (PROCESS; Model 4) was used. After controlling for possible effects of postgraduates' demographic characteristics, the results $(N=5000)$ indicated that the mediating roles of psychological capital (indirect effect $=0.346, \mathrm{SE}=0.060$, $95 \% \mathrm{CI}=[0.239,0.474])$ on the relationship between postgraduate competence and academic research performance was significant due to the fact that the $95 \%$ confidence intervals excluded zero.

We then tested whether psychological capital fully or partially mediated the relationship between postgraduate competence and academic research performance by examining whether the direct effect of postgraduate competence on academic research performance was statistically significant. As can be seen in Model 2 of Table 5, the direct effect of postgraduate competence on academic research performance was still statistically significant and was reduced when the mediator was included $(\beta=0.308, p<0.001)$, supporting an inference of partial mediation. 
Table 5. The results of hierarchical regression analyses on mediating effect.

\begin{tabular}{ccc}
\hline \multirow{2}{*}{ Variables } & \multicolumn{2}{c}{ Academic Research Performance } \\
\cline { 2 - 3 } & Model 1 & Model 2 \\
\cline { 2 - 3 } Gender & -0.037 & -0.020 \\
Age & -0.003 & 0.003 \\
Grade & -0.035 & -0.033 \\
Major & -0.098 & $-0.145^{* * *}$ \\
Postgraduate competence & $0.680^{* * *}$ & $0.308^{* * *}$ \\
Psychological capital & & $0.497^{* * *}$ \\
$\Delta \mathrm{R}^{2}$ & $0.483^{* *}$ & $0.572^{* *}$ \\
\hline Notes: $^{* *} p \leq 0.01$; $^{* * *} p \leq 0.001$. & &
\end{tabular}

\section{Discussion and Conclusions}

\subsection{Conclusions}

Higher education institutions play a critical role in societal transformation toward sustainability through the development of students' academic research abilities. With the aim of fostering sustainable social and economic development, it is essential to understand what academic research abilities postgraduate students should have and how postgraduate competence affect academic research performance in a rapidly changing society. Given this context, this study was conducted in order to develop an instrument for measuring postgraduate competence and examined the relationships between postgraduate competence and academic research performance within the Chinese educational context.

Firstly, our findings showed that postgraduate competence was composed of six factors, and the validation of the instrument indicated sound psychometric properties. This study identified and developed the measurement instrument for postgraduate competence using deductive and inductive approaches from the perspectives of professional researchers and postgraduate learning environments. We used two independent samples to validate a new measure of postgraduate competence in universities. Results provided robust evidence of our measure's construct validity and reliability through an exploratory and confirmatory factor analysis. The postgraduate competence was a multidimensional construct composed of six dimensions - self-management, research ability, attitude quality, psychological quality, research methods, and professional knowledge. The results of this research partly supported the findings of Munangatire and McInerney [20] and Villardón-Gallego et al. [58], which developed a procedure for designing a tool for the evaluation of competences. In addition, the characteristics of postgraduate academic training and psychological quality issues were taken into consideration in the development of the measurement instrument for postgraduate competence. It implied that postgraduate competence extended from the behavioral aspect to the psychological and cognitive aspects. It was meaningful that we focused more on psychological quality in the academic research environment as postgraduate students were expected to possess good psychological quality.

Secondly, our study corroborated and went deeper into the relationship between postgraduate competence and academic research performance. On the one hand, the results obtained revealed that postgraduate competence positively predicted academic research performance, which was consistent with the conclusion reported in prior research $[14,16]$. On the other hand, unlike previous studies that confirmed the relationship between postgraduate competence and academic research performance, the more specific aspects of postgraduate competence were linked to academic research performance. To be specific, research abilities, attitude qualities, research methods, and professional knowledge mainly affected academic research attitude. Research abilities, psychological qualities, and professional knowledge played prominent roles in shaping postgraduate students' academic research behavior. Research abilities, attitude qualities, and professional knowledge were prominent factors affecting academic research achievements. These findings enhance the understanding of the relationship between postgraduate competence and academic research performance. 
Thirdly, our study proved that psychological capital played a mediating role between postgraduate competence and academic research performance. Our findings demonstrated that competence could be positively transmitted through a specific psychological resourcepsychological capital. This finding was consistent with the prior research on psychological capital, which had demonstrated that psychological capital as an important psychological resource could promote the positive academic outcomes of postgraduate students [59,60]. Moreover, this result was in line with the job demands-resources model, which suggested that individuals could use their resources to deal with different challenges and meet academic research demands to achieve academic outcomes [61]. Competence was considered to be an external ability resource and psychological capital can be viewed as a positive psychological resource [59]. Individuals with high levels of competence were more likely to resort to positive psychological resources when they were presented with obstacles and challenges in academic research. Postgraduate students draw from personal resources, which enable them to exhibit high self-efficacy, hope, optimism, and resilience to move towards flourishing and success at the performance of challenging academic tasks [46].

\subsection{Theoretical and Practical Implications}

The present study had both theoretical and practical implications. At a theoretical level, it filled an existing gap in the literature and represented an important step forward for the relationship between postgraduate competence and academic research performance. Firstly, our research developed a measurement instrument that could assess postgraduate competence. As mentioned above, the characteristics of postgraduate academic training and psychological quality issues were not considered in existing scales of competence. This finding consequently motivated us to conceptualize postgraduate competence as an integration of diverse elements, thus facilitating a more efficient assessment; the measurement instrument developed will enable further quantitative research on postgraduate competence.

Secondly, our study went deeper into the identification of the specific aspects of postgraduate competence that were directly related to academic research performance, and therefore, to school adjustment. This was important because despite documentation by different studies of the relationship between competence and academic research performance $[16,17]$, none had clarified which specific aspects of this construct were significantly associated with postgraduate students' academic research performance. As a result, this study enriched our understanding of how postgraduate competence affected academic research performance.

Thirdly, our study added to the scholarly understanding of the mechanism through which postgraduate competence had a positive association with academic research performance by demonstrating the mediating effect of psychological capital. Therefore, this study enriched the application scope and specific mechanism of psychological capital and provided a reference for future relevant research.

At a practical level, this study also offered several practical implications for sustainability and sustainable development in higher education. First of all, the instrument in this article can be approved for practical application in the measurement of different dimensions of postgraduate competence. Our work provided a valid empirically and statistically assessed pool of competences developed through postgraduate training education. It is beneficial to provide some inspirations for the reform of postgraduate student training models [8]. Higher education institutions are encouraged to actively establish a competencebased evaluation system that is based on postgraduate competence [19], and consider it as a suitable practical tool to help postgraduate students value what practical competence they should have during academic training, and to further analyze and highlight the balance between postgraduate competence and the demands of academic research.

Secondly, given the positive role of postgraduate competence in academic research performance, higher education institutions are advised to design and implement interventions to improve academic research performance focusing on the specific aspects of postgraduate competence that have been shown to have a relationship with it, the ultimate aim of which 
is to improve academic research and promote sustainable education development [35]. According to the results, higher education institutions are encouraged to take the following measures to improve academic research performance: (a) focus on cultivating postgraduate students' research capabilities and inspiring postgraduate students' creativity, (b) stimulate the interest and passion of postgraduate students for participation in academic research practices [61], (c) pay attention to subject knowledge and interdisciplinary knowledge education to optimize their knowledge structure. In contrast, it should be noted that among the six dimensions of postgraduate competence, research abilities have the strongest positive association with three dimensions of academic research performance. In order for society to be sustainable in the future, universities should actively accept academic research demands for cultivating postgraduate research abilities [62], and postgraduate students should be expected to make up for the disadvantages of research abilities and promote the enhancement of scientific research capabilities [63].

Thirdly, considering the positive effect of psychological capital, we suggest that higher education institutions also attempt to establish formal psychological counseling and academic advisor programs, which have been proven to effectively promote the level of psychological capital [64-66]. During the cultivation of postgraduate students' training, we should pay attention to strengthening the psychological capital intervention with postgraduate students and stimulate their positive psychological resources. Through psychological counseling and academic advisors, it is expected that the development of resilience and optimism could help postgraduate students overcome obstacles to academic achievement and enhance their ability in scientific research and innovation; the improvement of postgraduates' self-efficacy and hope could drive them to form strong academic self-confidence and research ability. Therefore, academic research performance can potentially be developed and improved.

\subsection{Limitations and Future Research Directions}

In this study, there were a few limitations that needed to be addressed. Firstly, although the sample data was collected from two time periods, it was only based on students' self-reports. Although this method is scientific and reasonable, it lacks mutual verification from multiple perspectives. In order to minimize the impact of common method bias and improve the credibility of the data, future research should consider the use of pairing to collect data from different sources. Secondly, although successful validation of the development model supports its effectiveness, the research reported in this study was based on correlation and regression analysis, not experimental design. This means that the evidence for the causal relationship inferred by the final model is limited. The causal relationship between the variables should be further explored by a longitudinal or experimental study in subsequent studies. Thirdly, follow-up studies can also be conducted longitudinally to track the impact of postgraduate psychological capital and competence at different stages of their studies. The effect of postgraduate competence on academic research performance may be more pronounced with an increase in length of postgraduate enrollment. Future research may also attempt to explore the mechanisms of competence in academic research performance from organizational environmental factors, such as knowledge sharing in the research team, academic atmosphere, and pressure. Finally, although the sample size of this present study meets the sample size standard recommended by Green's calculation [67], the samples are from Chinese universities, and we cannot be certain of the extent to which our findings are generalizable to other countries, especially those from Western cultures. Therefore, it is necessary for future studies to explore the connotation of postgraduate competence and its impact on academic research performance through larger samples and cross-cultural research. 
Author Contributions: J.G. and Z.C. designed the research framework, wrote the paper, and analyzed the data. J.G. edited the paper. B.Z. provided valuable suggestions. All authors have read and agreed to the published version of the manuscript.

Funding: This work was supported by the Key Project of Chinese National Social Science Research Fund (20AAZD019), Huazhong University of Science and Technology Teaching Research Project (2020126), Fundamental Research Funds for the Central Universities (HUST2019), and Post-project from the Social Science Fund of the Ministry of Education (18JHQ080).

Institutional Review Board Statement: Not applicable.

Informed Consent Statement: Informed consent was obtained from all subjects involved in the study.

Data Availability Statement: The data presented in this study are available on request from the corresponding author. The data are not publicly available due to them containing information that could compromise research participant privacy/consent.

Acknowledgments: The authors would like to express their gratitude to the reviewers and magazine editors for their efforts to improve the quality of this paper.

Conflicts of Interest: No potential conflicts of interest were reported by the authors.

\section{References}

1. Waltner, E.-M.; Rieß, W.; Mischo, C. Development and Validation of an Instrument for Measuring Student Sustainability Competencies. Sustainability 2019, 11, 1717. [CrossRef]

2. UNESCO. Issues and Trends in Education for Sustainable Development; UNESCO: Paris, France, 2018.

3. Keinänen, M.; Ursin, J.; Nissinen, K. How to measure students' innovation competences in higher education: Evaluation of an assessment tool in authentic learning environments. Stud. Educ. Eval. 2018, 58, 30-36. [CrossRef]

4. Rivera, F.M.-L.; Hermosilla, P.; Delgadillo, J.; Echeverría, D. The Sustainable Development Goals (SDGs) as a Basis for Innovation Skills for Engineers in the Industry 4.0 Context. Sustainability 2020, 12, 6622. [CrossRef]

5. Squicciarini, M.P.; Voigtländer, N. Human Capital and Industrialization: Evidence from the Age of Enlightenment. Q. J. Econ. 2015, 130, 1825-1883. [CrossRef]

6. Xiao, H.; Mao, J. Effects of postgraduate education on technological innovation: A study based on the spatial Durbin model. Asia Pac. Educ. Rev. 2021, 22, 89-99. [CrossRef]

7. Wang, C.; Yang, J.; Cheng, Z.; Ni, C. Postgraduate Education of Board Members and R\&D Investment-Evidence from China. Sustainability 2019, 11, 6524. [CrossRef]

8. Durette, B.; Fournier, M.; Lafon, M. The core competencies of PhDs. Stud. High. Educ. 2016, 41, 1355-1370. [CrossRef]

9. Pearson, M.; Cumming, J.; Evans, T.; Macauley, P.; Ryland, K. How shall we know them? Capturing the diversity of difference in Australian doctoral candidates and their experiences. Stud. High. Educ. 2011, 36, 527-542. [CrossRef]

10. Zhao, X.; Yin, H.; Fang, C.; Liu, X. For the Sustainable Development of Universities: Exploring the External Factors Impacting Returned Early Career Academic's Research Performance in China. Sustainability 2021, 13, 1333. [CrossRef]

11. Colmar, S.; Liem, G.A.D.; Connor, J.; Martin, A.J. Exploring the relationships between academic buoyancy, academic self-concept, and academic performance: A study of mathematics and reading among primary school students. Educ. Psychol. 2019, 39, 1068-1089. [CrossRef]

12. Mróz, A.; Ocetkiewicz, I. Creativity for Sustainability: How Do Polish Teachers Develop Students' Creativity Competence? Analysis of Research Results. Sustainability 2021, 13, 571. [CrossRef]

13. Purcell, W.M.; Henriksen, H.; Spengler, J.D. Universities as the engine of transformational sustainability toward delivering the sustainable development goals: "Living labs" for sustainability. Int. J. Sustain. High. Educ. 2019, 20, 1343-1357. [CrossRef]

14. Humphreys, L.; Crino, R.; Wilson, I. Psychological functioning predicts competence development for postgraduate students of professional psychology. Train. Educ. Prof. Psychol. 2017, 11, 49-56. [CrossRef]

15. Samarakoon, L.; Fernando, T.; Rodrigo, C.; Rajapakse, S. Learning styles and approaches to learning among medical undergraduates and postgraduates. BMC Med. Educ. 2013, 13, 42. [CrossRef] [PubMed]

16. Garcia, O.; López, F.; Icaran, E.; Burgos, S. Relationship between general intelligence, competences and academic achievement among university students. Personal. Individ. Differ. 2014, 60, S67. [CrossRef]

17. Nwosu, J.C.; John, H.C.; Izang, A.A.; Akorede, O.J. Assessment of information and communication technology (ICT) competence and literacy skills among undergraduates as a determinant factor of academic achievement. Educ. Res. Rev. 2018, 13, 582-589. [CrossRef]

18. Carmona-Halty, M.; Salanova, M.; Schaufeli, W.B. The strengthening starts at home: Parent-child relationships, psychological capital, and academic performance-A longitudinal mediation analysis. Curr. Psychol. 2020, 2020, 1-9. [CrossRef]

19. Liu, Y.; Yin, Y.; Wu, R. Measuring graduate students' global competence: Instrument development and an empirical study with a Chinese sample. Stud. Educ. Eval. 2020, 67, 100915. [CrossRef] 
20. Munangatire, T.; McInerney, P. Nursing students' conceptions of competence and the learning processes that support the development of competence: A phenomenographic study. Adv. Health Sci. Educ. 2021, 1-20. [CrossRef]

21. Spencer, L.M.; Spencer, S.M. Competence at Work: Models for Superior Performance; Wiley \& Sons, Inc.: New York, NY, USA, 1993.

22. Gómez, M.; Aranda, E.; Santos, J. A competency model for higher education: An assessment based on placements. Stud. High. Educ. 2016, 42, 2195-2215. [CrossRef]

23. Velasco-Martínez, L.-C.; Tójar-Hurtado, J.-C. Competency-Based Evaluation in Higher Education-Design and Use of Competence Rubrics by University Educators. Int. Educ. Stud. 2018, 11, 118-132. [CrossRef]

24. Asif, M.; Awan, M.U.; Khan, M.K.; Ahmad, N. A model for total quality management in higher education. Qual. Quant. 2013, 47, 1883-1904. [CrossRef]

25. Van Loo, J.; Semeijn, J. Defining and Measuring Competences: An Application to Graduate Surveys. Qual. Quant. 2004, 38, 331-349. [CrossRef]

26. Dresel, M.; Schmitz, B.; Schober, B.; Spiel, C.; Ziegler, A.; Engelschalk, T.; Steuer, G.; Jöstl, G.; Klug, J.; Roth, A.; et al. Competencies for successful self-regulated learning in higher education: Structural model and indications drawn from expert interviews. Stud. High. Educ. 2015, 40, 454-470. [CrossRef]

27. Musekamp, F.; Pearce, J. Assessing engineering competencies: The conditions for educational improvement. Stud. High. Educ. 2015, 40, 505-524. [CrossRef]

28. Fernández-Rodríguez, C.; Soto-López, T.; Cuesta, M. Needs and demands for psychological care in university students. Psicothema 2019, 31, 414-421. [CrossRef]

29. Rüppel, F.; Liersch, S.; Walter, U. The influence of psychological well-being on academic success. J. Public Health 2015, 23, 15-24. [CrossRef]

30. Honicke, T.; Broadbent, J. The influence of academic self-efficacy on academic performance: A systematic review. Educ. Res. Rev. 2016, 17, 63-84. [CrossRef]

31. Zong, X.; Zhang, L.; Yao, M. Parental involvement and Chinese elementary students' achievement goals: The moderating role of parenting style. Educ. Stud. 2018, 44, 341-356. [CrossRef]

32. Kaplan, A.; Maehr, M.L. The Contributions and Prospects of Goal Orientation Theory. Educ. Psychol. Rev. 2006, 19, 141-184. [CrossRef]

33. Fromuth, M.E.; Bass, J.E.; Kelly, D.B.; Davis, T.L.; Chan, K.L. Academic entitlement: Its relationship with academic behaviors and attitudes. Soc. Psychol. Educ. 2019, 22, 1153-1167. [CrossRef]

34. Vajta, K. Self-evaluation in higher education: An educational tool for learning to learn. Moderna Sprak 2012, 106, 188-202.

35. Spöttl, G. Competence modeling and measurement in engineering mechanics. In Competence-Based Vocational and Professional Education; Mulder, M., Ed.; Springer: Cham, Switzerland, 2017; pp. 863-881.

36. Müller-Frommeyer, L.C.; Aymans, S.C.; Bargmann, C.; Kauffeld, S.; Herrmann, C. Introducing Competency Models as a Tool for Holistic Competency Development in Learning Factories: Challenges, Example and Future Application. Procedia Manuf. 2017, 9 , 307-314. [CrossRef]

37. Hobfoll, S.E. Social and Psychological Resources and Adaptation. Rev. Gen. Psychol. 2002, 6, 307-324. [CrossRef]

38. Ferla, J.; Valcke, M.; Schuyten, G. Judgments of self-perceived academic competence and their differential impact on students achievement motivation, learning approach, and academic performance. Eur. J. Psychol. Educ. 2010, 25, 519-536. [CrossRef]

39. Ren, X.; Tong, Y.; Peng, P.; Wang, T. Critical thinking predicts academic performance beyond general cognitive ability: Evidence from adults and children. Intelligence 2020, 82, 101487. [CrossRef]

40. Hu, M.-L.I.-C.M.; Horng, J.-S.; Teng, C.-C. Developing a Model for an Innovative Culinary Competency Curriculum and Examining Its Effects on Students' Performance. J. Creat. Behav. 2016, 50, 193-202. [CrossRef]

41. Luthans, F.; Avey, J.B.; Avolio, B.J.; Norman, S.M.; Combs, G.M. Psychological capital development: Toward a micro-intervention. J. Organ. Behav. 2006, 27, 387-393. [CrossRef]

42. Yu, B.; Mak, A.S.; Bodycott, P. Psychological and academic adaptation of mainland Chinese students in Hong Kong universities. Stud. High. Educ. 2019, 1-13. [CrossRef]

43. Folkman, S. Stress, coping, and hope. Psychol. Oncol. 2010, 19, 901-908. [CrossRef] [PubMed]

44. Liao, R.X.; Liu, Y.H. The impact of structural empowerment and psychological capital on competence among Chinese baccalaureate nursing students: A questionnaire survey. Nurs. Educ. Today 2016, 36, 31-36. [CrossRef] [PubMed]

45. Bouzari, M.; Karatepe, O.M. Test of a mediation model of psychological capital among hotel salespeople. Int. J. Contemp. Hosp. Manag. 2017, 29, 2178-2197. [CrossRef]

46. Youssef, C.M.; Luthans, F. Positive Organizational Behavior in the Workplace: The impact of hope, optimism, and resilience. J. Manag. 2007, 33, 774-800. [CrossRef]

47. Luthans, B.C.; Luthans, K.W.; Jensen, S.M. The Impact of Business School Students' Psychological Capital on Academic Performance. J. Educ. Bus. 2012, 87, 253-259. [CrossRef]

48. Ouweneel, E.; Le Blanc, P.M.; Schaufeli, W.B. Flourishing students: A longitudinal study on positive emotions, personal resources, and study engagement. J. Posit. Psychol. 2011, 6, 142-153. [CrossRef]

49. Hinkin, T.R. A Brief Tutorial on the Development of Measures for Use in Survey Questionnaires. Org. Res. Methods 1998, 1, 104-121. [CrossRef] 
50. Hu, L.T.; Bentler, P.M. Cutoff criteria for fit indexes in covariance structure analysis: Conventional criteria versus new alternatives. Struct. Equ. Model. 1999, 6, 1-55. [CrossRef]

51. Bollen, K.A. Structural Equations with Latent Variables; John Wiley and Sons, Inc.: New York, NY, USA, 1989 ; pp. $256-289$.

52. Fornell, C.; Larcker, D.F. Evaluating Structural Equation Models with Unobservable Variables and Measurement Error. J. Mark. Res. 1981, 18, 39-50. [CrossRef]

53. Williams, L.J.; Vandenberg, R.J.; Edwards, J.R. 12 Structural Equation Modeling in Management Research: A Guide for Improved Analysis. Acad. Manag. Ann. 2009, 3, 543-604. [CrossRef]

54. Rhee, B.S.; Kim, S. Differential pathways to generic skills development of male and female college students in Korea. Asia Pac. Educ. Rev. 2012, 13, 677-690. [CrossRef]

55. Cabezas-González, M.; Casillas-Martín, S.; García-Peñalvo, F.J. The Digital Competence of Pre-Service Educators: The Influence of Personal Variables. Sustainability 2021, 13, 2318. [CrossRef]

56. Hair, J.F.; Anderson, R.E.; Tatham, R.L.; Black, W.C. Multivariate Data Analysis, 5th ed.; Prentice Hall: Trenton, NJ, USA, 1998.

57. Hayes, A.F. Introduction to Mediation, Moderation, and Conditional Process Analysis: A Regression-Based Approach, 2nd ed.; Guilford Press: New York, NY, USA, 2013; pp. 86-93.

58. Villardón-Gallego, L.; Yániz, C.; Achurra, C.; Iraurgi, I.; Aguilar, M.D.C. Learning competence in university: Development and structural validation of a scale to measure. Rev. Psicodidact. 2013, 18, 357-374. [CrossRef]

59. Siu, O.L.; Bakker, A.B.; Jiang, X. Psychological Capital Among University Students: Relationships with Study Engagement and Intrinsic Motivation. J. Happiness Stud. 2014, 15, 979-994. [CrossRef]

60. Kool, A.; Mainhard, M.T.; Jaarsma, A.D.C.; Van Beukelen, P.; Brekelmans, M. Do Students with Varying Academic Ability Benefit Equally from Personal Qualities? Applying a Trait and State Perspective. Res. High. Educ. 2018, 59, 1021-1034. [CrossRef]

61. Gusy, B.; Woerfel, F.; Lohmann, K. Exhaustion and engagement in university students: An application of the job demandsresources model. Z. Gesundheitspsychol. 2016, 24, 41-53. [CrossRef]

62. Lim, K.; Eom, S.; Kim, D.; Oh, M. Understanding Gender Differences in Students' Perceptions of Competency Certification for Enhancing Sustainability in Higher Education. Sustainability 2020, 12, 8233. [CrossRef]

63. Richardson, M.; Abraham, C.; Bond, R. Psychological correlates of university students' academic performance: A systematic review and meta-analysis. Psychol. Bull. 2012, 138, 353-387. [CrossRef]

64. Tang, J.-J. Psychological Capital and Entrepreneurship Sustainability. Front. Psychol. 2020, 11, 866. [CrossRef]

65. Asgari, S.; Carter, F., Jr. Peer mentors can improve academic performance: A quasi-experimental study of peer mentorship in introductory courses. Teach. Psychol. 2016, 43, 131-135. [CrossRef]

66. Sánchez-Cardona, I.; Ortega-Maldonado, A.; Salanova, M.; Martínez, I.M. Learning goal orientation and psychological capital among students: A pathway to academic satisfaction and performance. Psychol. Sch. 2021, 1-14. [CrossRef]

67. Green, S.B. How Many Subjects Does It Take To Do A Regression Analysis. Multivar. Behav. Res. 1991, 26, 499-510. [CrossRef] [PubMed] 